\title{
MÚSICA E DOR CRÔNICA MÚSCULOESQUELÉTICA: O POTENCIAL EVOCATIVO DE IMAGENS MENTAIS ${ }^{1}$
}

Eliseth Ribeiro Leão

Maria Julia Paes da Silva ${ }^{3}$

Leão ER, Silva MJP. Música e dor crônica músculoesquelética: o potencial evocativo de imagens mentais. Rev Latino-am Enfermagem 2004 março-abril; 12(2):235-41.

Noventa mulheres com diagnósticos de fibromialgia, lesão por esforços repetitivos/doenças osteoarticulares, relacionadas ao trabalho (LER/DORT), e afecções relacionadas à coluna vertebral foram submetidas à audição individual de três peças musicais. Os dados foram obtidos por meio de entrevista e a intensidade da dor foi avaliada pela escala numérica verbal (0-10) antes e ao término da audição musical. As imagens mentais foram quantificadas mediante a análise de desenhos realizados durante cada audição. Os três grupos apresentaram redução estatisticamente significativa da intensidade da dor ao final da audição musical $(p<0,001)$. As imagens mentais não diferiram quantitativamente, entre Ravel e Wagner. O Mix apresentou resultados quantitativamente inferiores. As estruturas musicais se relacionaram à produção de imagens e o efeito terapêutico observado, sugerindo que análises nesse sentido podem contribuir para a utilização da música pela Enfermagem.

DESCRITORES: musicoterapia; dor; terapias alternativas; enfermagem

\section{MUSIC AND CHRONIC MUSCULAR-SKELETAL PAIN: THE EVOCATIVE POTENTIAL OF MENTAL IMAGES}

Ninety women with diagnosed fibromyalgia, work-related repetitive strain injury/osteoarticular diseases (RSI) and diseases related to the spinal column were submitted to individual listening of three musical pieces. Data were obtained by means of interviews and pain intensity was evaluated by the verbal numeric scale (0-10) before and after listening to the music. The mental images were quantified by analyzing the drawings made during each listening session. The three groups presented a statistically significant reduction in pain intensity at the end of the listening session $(p<0.001)$. The mental images did not differ in quantity, between Ravel and Wagner. The Mix presented quantitatively lower results. The musical structures related to the production of images and the observed therapeutic effect suggests that structural analyses may contribute to the use of music by nursing.

DESCRIPTORS: music therapy; pain; alternative therapies; nursing

\section{LA MÚSICA Y EL DOLOR CRÓNICO MÚSCULOESQUELÉTICO: EL POTENCIAL EVOCATIVO DE IMÁGENES MENTALES}

Noventa mujeres con diagnósticos de fibromialgia, lesión por esfuerzos repetitivos/enfermedades osteoarticulares relacionadas al trabajo (LER/DORT) y afecciones relacionadas con la columna vertebral fueron sometidas a una audición individual de tres piezas musicales. Los datos fueron obtenidos por medio de entrevista, y la intensidad del dolor fue evaluada por la escala numérica verbal (0-10) antes y al finalizar la audición musical. Las imágenes mentales fueron cuantificadas mediante el análisis de dibujos realizados durante cada audición. Los tres grupos presentaron una reducción estadísticamente significativa de intensidad del dolor al final de la audición musical ( $p<0,001)$. Las imágenes mentales no difieren cuantitativamente, entre Ravel e Wagner. El Mix presentó resultados cuantitativamente inferiores. Las estructuras musicales se relacionaron con la producción de imágenes y al efecto terapéutico observado, sugiriendo que el análisis en ese sentido puede contribuir para la utilización de la música por parte de la Enfermería.

DESCRIPTORES: musicoterapia; dolor; terapias alternativas; enfermería

\footnotetext{
${ }^{1}$ Excerto de tese de doutorado apresentada à Escola de Enfermagem da Universidade de São Paulo, em setembro de $2002 ;{ }^{2}$ Doutor em Enfermagem, Assessora de Pesquisa Científica do Hospital Samaritano, e-mail: eliseth.leao@samaritano.com.br; ${ }^{3}$ Professor Livre-Docente da Escola de Enfermagem da Universidade de São Paulo, e-mail: juliaps@usp.br
} 
INTRODUÇÃO

A música tem acompanhado o homem desde os primórdios da humanidade, e por mais que a ciência tenha avançado, a compreensão de como ela exerce influência sobre os seres humanos constitui, ainda, um desafio e um campo a ser explorado.

Sabemos que a música abrange as seguintes dimensões humanas: a biológica, a mental, a emocional e a espiritual. Entretanto, muitos dos caminhos pelos quais isso ocorre, ainda nos são um tanto quanto desconhecidos.

Independente disso, temos observado também, ao longo da história da humanidade e da própria Medicina, a sua utilização como recurso terapêutico ${ }^{(1)}$.

$\mathrm{Na}$ Enfermagem, sua utilização com finalidade terapêutica se iniciou com Florence Nightingale ${ }^{(2)}$, seguida, anos mais tarde, por Isa Maud Ilsen e Harryet Seymor no cuidado aos feridos das I e II Guerras Mundiais ${ }^{(3)}$.

Tendo em vista, principalmente, a redução do estresse e ansiedade, passou a ser utilizada em diversas situações clínicas e no controle da dor sua utilização também tem sido apontada ${ }^{(4)}$.

A dor músculoesquelética é um dos mais importantes problemas de saúde pública enfrentado pelos países ocidentais. Os custos relacionados com aspectos médicos e sociais têm crescido incessantemente nas últimas décadas e atingem atualmente cifras da ordem de bilhões de dólares em vários países. O tratamento que busca a reversão desse quadro é multiprofissional e as medidas não farmacológicas constituem forma importante de intervenção de enfermagem.

Na nossa experiência temos utilizado a música como recurso complementar no tratamento da dor crônica músculoesquelética, integrando Programas Educativos em Dor Crônica. Esses programas são desenvolvidos por diversos profissionais da área da saúde com abordagem cognitivo-comportamental, objetivando o alívio da dor e melhora da qualidade de vida. Com a música, além dos relatos positivos na redução dos quadros dolorosos, chamou-nos a atenção as experiências imagéticas relatadas ao término de cada audição musical, levandonos a refletir sobre o papel das imagens mentais nos efeitos sobre a intensidade da dor.

Na literatura, alguns mecanismos são descritos para explicar esses efeitos como a indução de relaxamento, a liberação de endorfinas e a distração( ${ }^{(5)}$.

A utilização das imagens mentais no controle da dor é descrita desde a medicina primitiva da China, do Egito e da Índia, estabelecendo um elo de comunicação entre a percepção, a emoção e a mudança corporal. Assim sendo, a imaginação tem sido discutida como meio de alterar o foco perceptual da dor ${ }^{(4)}$. Indivíduos com dores crônicas têm a experiência dolorosa como foco central de sua atenção, e a utilização de imagens pode favorecer um deslocamento atencional com resultados terapêuticos.

Observamos que, quando as pessoas ouvem música, uma série de imagens é produzida, independentemente de sua preferência musical, ou seja, a música contém um potencial para evocá-las, que não constitui unidade de medida em si, mas possibilita a comparação quantitativa. Isso acontece porque nosso cérebro transforma quase todas as experiências que temos em imagens mentais. A música, por meio da sua linguagem de ritmo, melodia, forma, tom, harmonia, timbre, instrumentação e vozes, toca todos os níveis do nosso ser $e$ as nuances da estrutura musical afetam o fluxo de imagens $^{(6)}$, conduzindo-nos à idéia de que músicas diferentes, com diferentes estruturas musicais podem apresentar, também, diferentes potenciais para evocar a imaginação. As imagens decorrentes da audição musical erudita têm sido pouco investigadas ${ }^{(7)}$, uma das razões que nos levou à realização deste estudo.

Os critérios de utilização da música pela Enfermagem ainda constituem desafio. Conhecer o potencial evocativo do material sonoro oferecido aos indivíduos com dor crônica músculoesquelética pode configurar um primeiro passo nesse sentido, assim como pode levar-nos a avançar um pouco mais na compreensão da sua influência sobre o fenômeno doloroso.

\section{OBJETIVOS}

- Conhecer e comparar o potencial evocativo quantitativo de imagens mentais de três peças musicais, prédeterminadas, em mulheres com dor crônica músculoesquelética.

- Verificar o efeito global da audição musical sobre a intensidade da dor músculoesquelética.

\section{MATERIAL E MÉTODO}

O estudo realizado foi do tipo descritivo, exploratório, correlacional, comparativo com abordagem 
quantitativa. As sessões musicais foram realizadas individualmente e uma única vez, para cada paciente, no consultório do Ambulatório do Instituto de Ortopedia e Traumatologia do Hospital das Clínicas da Faculdade de Medicina da Universidade de São Paulo (IOTHCFMUSP), após aprovação do Comitê de Ética em Pesquisa da Escola de Enfermagem da Universidade de São Paulo e do consentimento formal da comissão científica da Instituição, no período de setembro de 2000 a junho de 2001.

A amostra, por conveniência, foi constituída por noventa mulheres com dor crônica músculoesquelética, atendidas ambulatorialmente no campo de estudo, voluntárias em participar da pesquisa, que assinaram, após apresentação dos objetivos da pesquisa, o Termo de Consentimento Livre e Esclarecido (conforme o previsto pelo Conselho Nacional de Saúde, Resolução no 196, de 10 de outubro de 1996), garantindo sigilo sobre sua identidade e assegurando a retirada do consentimento em qualquer etapa do estudo. Segundo a etiologia da dor, foram divididas em três grupos: 30 mulheres com diagnóstico de fibromialgia, 30 mulheres com diagnóstico de Lesões por Esforços Repetitivos/Doenças Osteoarticulares Relacionadas ao Trabalho (LER/DORT) e 30 mulheres com afecções da coluna vertebral.

Os dados foram obtidos por meio de formulário que permitiu caracterizar a amostra quanto à idade, grau de instrução, estado civil, religião, situação profissional, preferência e formação musicais. A intensidade álgica foi avaliada antes e após a audição de cada peça musical, numa escala verbal numérica de 0 a 10 , na qual zero corresponde à ausência de dor e 10 à pior dor imaginável. Foram avaliadas, ainda, as seguintes variáveis: seqüência musical, utilização de medicamentos analgésicos, etiologia da dor e produção de imagens mentais para cada audição musical.

A escolha do repertório fundamentou-se em selecionar duas composições eruditas de alto teor artístico, bastante diferenciadas quanto à sua proposta musical, e uma terceira possibilidade como controle, que denominamos Mix, por se tratar da junção de diversos trechos de músicas eruditas. Essa montagem foi feita de forma com que as músicas parecessem de fato entrecortadas, desordenando, tanto quanto possível, a estrutura musical, em relação às outras duas, por meio da mistura proposital de formas estruturais diferentes, com múltiplas variações quanto à duração (andamento, ritmo e compasso), dinâmica (intensidade do som), timbres e variedade estilística.

Denominamos como Música A, o "Bolero" de Maurice Ravel, de música B, o Prelúdio para o Ato I da ópera Lohengrin, de Richard Wagner, e de música $\mathrm{C}$, o Mix, em oposição às estruturas musicalmente bem definidas das Músicas $A$ e $B$. As músicas foram dispostas em três seqüências musicais: $A B C, B C A$ e $C A B$, sendo cada uma delas ouvidas por 10 pacientes de cada um dos três grupos estudados.

Durante a execução de cada trecho musical foi solicitado às pesquisadas que desenhassem as imagens que the ocorreram à mente enquanto ouviam a música, utilizando-se de lápis coloridos e folhas de sulfite A4. Os desenhos foram quantificados por número total de desenhos realizados (cada representação gráfica global correspondendo a uma folha de sulfite A4) e por número de objetos que os compunham (representações múltiplas, contidas em cada folha de sulfite A4, categorizadas por significado gráfico, por exemplo: flor,casa, sol, etc.), por grupo de pacientes e por peça musical, permitindo analisar comparativamente o potencial de evocação de imagens mentais das músicas entre si, ou seja, quantas imagens foram geradas em cada audição musical.

As análises quantitativas Descritiva e Inferencial foram adotadas neste estudo. A primeira foi feita sobre os dados que caracterizam a amostra, apresentando distribuições de freqüências, média, desvio padrão e intervalos de confiança de $95 \%$ na produção de estimativas intervalares. Para a realização de nossas inferências, adotamos os seguintes procedimentos estatísticos: Teste Qui-Quadrado de Associação e de Aderência (para verificação da associação entre etiologia e dor e medicamentos e dor), a Análise de Variância de KruskallWallis (associação entre seqüência musical e intensidade da dor) e o Teste de Wilcoxon (efeito da audição musical sobre a intensidade da dor). Em todas as análises inferenciais foi calculado o P-Value associado à Hipótese de Nulidade (Ho) adotada em cada teste. Neste estudo toda diferença cujo P-Value foi inferior a 0,05 foi considerada estatisticamente significante.

\section{RESULTADOS}

$\mathrm{Na}$ amostra estudada a média de idade foi de 45,50 anos (DP - desvio padrão de 11,68 anos), 
predominando a faixa etária de 34 a 45 anos $(47,78 \%)$, seguida da faixa etária de 46 a 57 anos (22,22\%). O grau de instrução predominante foi $1^{\circ}$ grau incompleto $(42,22 \%)$, seguido de $2^{\circ}$ grau completo $(22,22 \%)$. O estado civil 'casada' predominou (57,78\%). A maioria $(63,33 \%)$ pertencia à religião católica e 55,55\% desempenhava atividade profissional remunerada. Somente três pacientes haviam recebido formação musical específica e a preferência musical recaiu sobre diversos estilos musicais, correspondendo $14,44 \%$ da preferência para a música erudita.

A dor inicial moderada (escores entre 5,0 e 7,4) foi relatada por $43,33 \%$ do total das pacientes $(n=90)$, com média de intensidade de 4,6 (DP=3,08). Maior média de intensidade da dor inicial foi observada no Grupo de fibromialgia $(6,60-D P=2,74)$ em relação aos grupos de LER/DORT e Coluna $(p<0,05)$.

As médias de intensidade da dor inicial e após cada audição musical, por grupo, são apresentadas na Tabela 1.

Tabela 1 - Distribuição das médias e desvio padrão de intensidade da dor inicial e após cada audição musical, por grupos, segundo a etiologia da dor. São Paulo, 2001

\begin{tabular}{|c|c|c|c|c|}
\hline & Fibromialgia & LER/DORT & Coluna & Total \\
\hline Inicial & $6,60(2,74)$ & $4,06(2,96)$ & $3,50(2,66)$ & $4,72(3,08)$ \\
\hline Após $1^{a}$ audição & $5,05(2,98)$ & $3,21(2,81)$ & $2,11(2,34)$ & $3,46(2,96)$ \\
\hline Após $2^{\mathrm{a}}$ audição & $5,13(2,89)$ & $2,86(2,86)$ & $1,36(1,73)$ & $3,12(2,97)$ \\
\hline Após $3^{a}$ audição & $5,00(2,84)$ & $3,10(2,79)$ & $1,16(1,68)$ & $3,09(2,92)$ \\
\hline
\end{tabular}

Ao término das três audições, observamos, nos três grupos, aumento estatisticamente significativo $(p=0,021)$ de pacientes que apresentaram ausência total de dor, segundo avaliação numérica verbal (0-10), mostrado na Tabela 2.

Tabela 2 - Distribuição das pacientes segundo a etiologia e ausência de dor antes (inicial) e após (final) a audição das três peças musicais. São Paulo, 2001

\begin{tabular}{lcccc}
\hline & Fibromialgia & LER & Coluna & Total \\
\hline Ausência de dor inicial & 3 & 7 & 9 & 19 \\
Ausência de dor final & 5 & 10 & 18 & 33 \\
\hline
\end{tabular}

A intensidade da dor entre a avaliação inicial e a última audição musical sofreu redução estatisticamente significativa $(p<0,001)$ nos três grupos e no total das pacientes, conforme demonstra a Tabela 3.
Tabela 3 - Distribuição do efeito da audição musical sobre a intensidade da dor, segundo a etiologia. São Paulo, 2001

\begin{tabular}{lcccc} 
& Fibromialgia & LER/DORT & Coluna & Global \\
\hline Aumentou & 4 & 0 & 0 & 4 \\
Diminuiu & 19 & 14 & 19 & 52 \\
Não alterou & 7 & 16 & 11 & 34 \\
$\mathrm{p}^{\text {a }}$ & $<0,001^{*}$ & $<0,001^{*}$ & $<0,001^{*}$ & $<0,001^{*}$ \\
\hline
\end{tabular}

* A diferença é estatisticamente significativa $(p<0,05)$

a Foi realizado o teste de Wilcoxon nas comparações

O teste Qui-Quadrado de associação para a variável etiologia e dor inicial/final mostrou não haver associação estatisticamente significativa $(p=0,869)$. Pela aplicação do mesmo teste, observamos ausência de associação estatisticamente significativa $(p=0,181)$ entre a utilização de medicamentos e diminuição da dor após a audição musical.

A seqüência musical $C A B$ apresentou associação estatisticamente significativa $(p=0,005)$ somente para a intensidade da dor do Grupo de Coluna (menor redução da dor) ao término da 1a audição, ou seja, após o Mix.

Com relação à produção de desenhos, o Grupo de Fibromialgia elaborou 5 desenhos, o Grupo de LER/ DORT, 49 desenhos e o Grupo de Coluna fez 61 desenhos, totalizando 115 desenhos. Desses, 45 (39,13\%) foram feitos durante a audição da música de Wagner, 43 (37,38\%) durante a audição da música de Ravel e 27 (23,39\%) durante o Mix. A audição do Mix levou à maior ausência de imagens que resultou num número menor, estatisticamente significativo ( $p<0,0001)$, de desenhos elaborados em relação a Wagner e Ravel que, entre si, apresentaram produção quantitativa semelhante.

Considerando o número de objetos desenhados que compunha cada desenho, pudemos constatar que entre Ravel e Wagner, também, não houve diferença estatisticamente significativa $(p=0,404)$, pois, em Ravel, a análise permitiu verificar a existência de 278 objetos representados graficamente nos 43 desenhos elaborados e, em Wagner, 299 objetos desenhados nos 45 desenhos. No Mix, da mesma forma, que apresentou número inferior de desenhos em relação às duas outras peças musicais, observamos número inferior de objetos desenhados (162 objetos $-p<0,01)$.

\section{DISCUSSÃO DOS RESULTADOS}

A caracterização da amostra nos permitiu observar 
que a dor crônica músculoesquelética atinge mulheres na fase produtiva profissionalmente. Parcela significativa das pacientes era casada. A literatura sugere que indívíduos separados, divorciados ou viúvos apresentam maior risco para dor crônica e mais especificamente para dor crônica músculoesquelética ${ }^{(8)}$, não sendo completamente clara a influência de como a condição civil "casado" poderia proteger os indivíduos com dores crônicas, o que não foi observado nesse estudo, já que muitas pacientes eram casadas. Consideramos que as modificações relacionais pelas quais a sociedade vem passando, nos últimos anos, podem estar influenciando esse aspecto. $O$ distresse psicológico enfrentrado outrora por quem se via solitário, parece acometer, na atualidade, indivíduos que, por razões econômico-financeiras, não conseguem se separar, gerando desequilíbrio conjugal, levando a condição marital a perder sua "função protetora" em relação à dor.

Com relação ao universo sonoro-musical das pacientes, a maioria da amostra constituiu-se de não músicos, uma vez que somente três pacientes haviam recebido ensino formal em música. Normalmente a escuta musical feita por músicos diverge da realizada por não músicos, uma vez que os primeiros tendem a fazê-la analiticamente, podendo interferir nos efeitos da música sobre o ouvinte, o que não foi observado. A preferência musical recaiu sobre diversos estilos musicais, o que não interferiu também na audição musical erudita, ou seja, mesmo a música erudita não sendo o estilo preferido pela maioria das pacientes, não impediu a vivência observada no repertório apresentado.

A preferência musical, ou seja, colocar para o indivíduo ouvir a música que ele prefere, é preconizada por alguns musicoterapeutas, que têm abordagem diferenciada daquela utilizada pelos enfermeiros no cotidiano, uma vez que não há como dispor de discografia abrangente no ambiente hospitalar. Não entramos no mérito de qual seria a melhor abordagem, restringindonos somente àquela que consideramos melhor adequarse ao escopo das nossas atividades, focalizando mais a relação música/ouvinte, a despeito de sua preferência, ou seja, o que há na música e o que ela desperta em quem a ouve. A preferência musical na audição passiva traz consigo uma outra questão contraditória sob o ponto de vista terapêutico, que leva em consideração o princípio de ISO e deve ser cuidadosamente avaliada quando se propõe à utilização terapêutica da música. ISOS vem do grego e quer dizer igual. O princípio de ISO, que pode ser classificado em gestáltico, cultural, individual ou universal, é um conceito dinâmico que resume a noção de existência de um som, ou um conjunto de sons que caracterizam ou individualizam cada ser humano, condensando arquétipos sonoros $^{(9)}$ que podem estar contidos na música erudita, em particular nas Grandes Obras, em se tratando do ISO universal. Baseando-se nesse princípio, os estados de ânimo de um indivíduo podem ser alterados através da música. Para tanto, por exemplo, para minimizar a ansiedade de um indivíduo, ele seria levado a ouvir uma música com um padrão mais agitado para, paulatinamente, ir sendo substituído por um ritmo mais lento que pudesse favorecer um estado de relaxamento, como configurado na Roda dos Humores de Hevner, que apresenta oito qualidades de humor, compostas por adjetivos que se relacionam, mas diferem entre si e que, se sistematicamente utilizada, pode conduzir à transição suave de uma qualidade de humor para outra ${ }^{(1)}$. Se, hipoteticamente, esse fosse o objetivo terapêutico, a escolha do repertório pelo paciente poderia, dependendo do estilo musical preferido, mascarar um determinado estado de ânimo, dificultar seu diagnóstico ou, ainda, deixar de atender à real necessidade do paciente.

Consideramos que o princípio de $\mathrm{ISO}^{(9)}$, na categoria individual ou grupal, pode favorecer, por exemplo, a atuação do enfermeiro em psiquiatria, mais do que em outras áreas e que maior respaldo para a prática na clínica em dor, no que se refere à audição passiva, seja encontrada no ISO universal. A questão do controle do paciente sobre o ambiente, que fatalmente se impõe, pode ser contornada por seleções musicais pré-determinadas, nas quais o paciente escolhe uma música (atendendo, de certa forma, a preferência) dentre aquelas em que o enfermeiro tenha maior conhecimento, tanto sobre seus efeitos, quanto à terapêutica a que se propõe em cada situação clínica.

A intensidade da dor relatada pelas pacientes apresentou-se mais elevada no grupo de fibromialgia, sofrendo redução proporcional após a audição musical em relação aos demais grupos.

Alguns aspectos podem ser apontados para a diferença observada: a dor na fibromialgia tem distribuição corporal generalizada, já na LER/DORT e no grupo de coluna, a dor encontra-se limitada a uma região do corpo, o que parece produzir, portanto, para as pacientes com fibromialgia, uma sensação de desconforto mais acentuada. A fibromialgia configura, ainda, uma síndrome, na qual a dor é um dos principais sintomas, mas não o 
único. Estão presentes, também, distúrbios do sono, fadiga, distúrbios intestinais funcionais, depressão e ansiedade ${ }^{(10)}$, características essas, excetuando-se as duas últimas, inexistentes ou menos expressivas nos dois outros grupos.

Esses sintomas principais e secundários imprimem sofrimento e desamparo, prejudicando essas pacientes em sua vida familiar, profissional e social, comprometendo a qualidade de vida. Isso também ocorre na dor músculoesquelética como um todo, mas, na amostra estudada, o impacto parece ter sido menor para LER/DORT e Coluna. A dor na fibromialgia é mais persistente e a remissão dos sintomas são raros e, quando ocorrem, são freqüentemente transitórios. Isso pode ter influenciado a resposta desse grupo quanto à tarefa de desenhar as imagens mentais que ocorriam durante a execução musical, uma vez que somente três pacientes com fibromialgia procederam à realização dos desenhos.

A audição musical, neste estudo, levou à redução estatisticamente significativa da dor para o global das pacientes, resultado esse corroborado por outros autores no alívio de outras dores crônicas ${ }^{(11)}$. Dentre os mecanismos que se relacionam com o alívio da dor, encontram-se a distração, a alteração do foco perceptual e a liberação de endorfinas ${ }^{(5)}$, como, também, o relaxamento ${ }^{(12)}$, conforme discutimos em estudo anterior $^{(13)}$, levando-nos a observar que as imagens mentais permeiam todos esses mecanismos. A música, dessa forma, permite escape temporário para "um mundo sem dor", sob o abrigo da imaginação(14).

As músicas selecionadas apresentaram potencial evocativo de imagens diferenciado entre as músicas estruturadas (Ravel e Wagner) e o Mix que levaram cada ouvinte a imaginar muitos quadros mentais. Em Ravel e Wagner, o número de imagens desenhadas foi semelhante. Entretanto, no Mix, o número de imagens foi estatisticamente menor, demonstrando que a estrutura musical, a forma pela qual o compositor manipula os elementos musicais repercute diretamente na experiência do ouvinte. Esses achados parecem ir mais ao encontro da visão absolutista de como a música produz reações humanas. Nessa teoria, acredita-se que a música tem valor e significados intrínsecos e que suas características estruturais provocam sentimentos e emoções nos ouvintes, com repercussões variadas ${ }^{(15)}$. Por outro lado, embora a visão referencialista rejeite a hipótese de que a música produza reações humanas sem associações com objetos ou eventos extramusicais ${ }^{(15)}$, mantemos nossa posição de que essas teorias não se excluem, mas se complementam, levando a uma resposta comportamental e estética à música, que influencia, inclusive, o fluxo de imagens mentais.

\section{CONSIDERAÇÕES FINAIS}

Este estudo permitiu-nos verificar que músicas com estruturas formais bem definidas apresentam maior potencial para evocar imagens que material sonoro não estruturado musicalmente. A audição musical proporcionou experiência rica em imagens mentais que não diferiu quantitativamente entre Ravel e Wagner e, sim, entre elas e o Mix, que apresentou menor quantidade de imagens.

Observamos também, redução dos escores de intensidade álgica favorecida pela audição musical e as imagens mentais decorrentes.

Infelizmente, por questões metodológicas, não podemos estabelecer o quanto de efeito residual pode ter sido mantido de uma peça para a outra, uma vez que a audição foi seqüencial e a subjetividade pode ter se detido mais num aspecto ou outro da experiência. Não podemos afirmar, até mesmo, o quanto isso interferiu na execução dos desenhos ou no processo como um todo, o que merece ser pesquisado com outra abordagem. Embora conscientes das limitações do nosso estudo, os resultados obtidos permitem-nos inferir que o estudo das imagens mentais decorrentes da audição musical erudita, particularmente, das obras apresentadas, pode constituir um caminho possível para o estabelecimento de critérios da utilização da música pela Enfermagem.

A investigação do estudo das imagens mentais deve ser aprofundada, principalmente, no que se refere aos aspectos qualitativos do conteúdo imagético, uma vez que sua análise pode revelar as sensações estéticas e significados simbólicos da experiência, levando-nos a maior aproximação das formas de atuação da música sobre o ser humano. 


\section{REFERÊNCIAS BIBLIOGRÁFICAS}

1. McClellan R. O poder terapéutico da música. São Paulo (SP): Siciliano; 1994.

2. Ninghtingale F. Notas em enfermagem: o que é e o que não é. São Paulo (SP): Cortez; 1989.

3. Davis WB, Gfeller KE, Thaut MH. An introduction to music therapy theory and practice. Dubuque: WCM Publishers; 1992. 4. McCaffery M, Beebe A. Pain: clinical manual for nursing pain. St. Louis: Mosby; 1989.

5. Campbell D. O efeito Mozart: explorando o poder da música para curar o corpo, fortalecer a mente e liberar a criatividade. Rio de Janeiro (RJ): Rocco; 2001.

6. Bush CA. A música e a terapia das imagens: caminhos para o eu interior. São Paulo (SP): Cultrix; 1995.

7. McKinney $\mathrm{CH}$. The effect of music on imagery. J Music Ther 1990; 27(1):34-46.

8. Magni G, Caldieron C, Rigatti-Luchini S, Merskey H. Chronic musculoskeletal pain and depressive symptoms in the general population. Pain 1990; (43):299-307.

9. Benenzon R. Teoria da musicoterapia. São Paulo (SP): Summus; 1988.

10. Martinez JE, Atra E, Fontana AM, Dacol E, Castro P, Amaral $\mathrm{R}$, Oliveira ST, Jorge T. Aspectos psicológicos em mulheres com fibromialgia. Rev Bras Reumatol 1992; 32(2):51-60.

11. Munroe S, Mount B. Music therapy in paliative care. CMAJ 1978; 119(4):1029-34

12. Paula AAD, Carvalho EC, Santos $C B$. The use of the "progressive muscle relaxation" technique for pain relief in gynecology and obstetrics. Rev Latino-am Enfermagem 2002; 10(5):654-9.

13. Dobbro ERL. A música como terapia complementar no cuidado de mulheres com fibromialgia. [dissertação]. São Paulo (SP): Escola de Enfermagem/USP; 1998.

14. Ortiz JM. O tao da música: utilizando a música para melhorar sua vida. São Paulo (SP): Mandarim; 1998.

15. Terwogt MM, Grinsven FV. Musical expression of mood states. Psychol Music 1991; (19):99-109. 